$R M x A C, \mathbf{5 2}, 19-20(2020)$

(C) 2020: Instituto de Astronomía, Universidad Nacional Autónoma de México

https://doi.org/10.22201/ia.14052059p.2020.52.07

\title{
SLR LATIN AMERICAN NETWORK AND ITS CONTRIBUTION TO THE ITRF 2014
}

\author{
A. M. Pacheco ${ }^{1}$, J. Quinteros ${ }^{1}$, R. Podestá ${ }^{1}$, P. Yanyachi ${ }^{2}$, M. Haefner ${ }^{3}$, H. Alvis Rojas ${ }^{1}$, A. Millan ${ }^{1}$, \\ J. M. Navarro ${ }^{1}$, J. M. Tapia ${ }^{1}$, and E. P. A. González ${ }^{1}$
}

\section{RESUMEN}

Dentro de la red global ILRS (International Laser Ranging Service), coexisten subredes continentales que llevan a cabo varios proyectos científicos. En particular, en América del Sur hay cuatro estaciones SLR bien ubicadas en el área. Este trabajo muestra las cuatro estaciones SLR (incluidas en los marcos de referencia internacionales actuales ITRF 2008 e ITRF 2014) y los próximos desafíos para esta técnica satelital en América Latina, considerando futuros proyectos de red.

\section{ABSTRACT}

Within the ILRS (International Laser Ranging Service) global network, continental subnets that carry out various scientific projects coexist. In particular, in South America there are four SLR stations well located within the region. This paper shows the four SLR stations (included in the current international reference frameworks ITRF 2008 and ITRF 2014) and the next challenges for this satellite technique in Latin America, considering future network projects.

Key Words: Geodesy

\section{INTRODUCTION}

SLR technique is a proven geodesic-astronomical discipline, with a significant potential contribution to the definition of reference systems (celestial and terrestrial), monitoring of Earth rotation, time scales, Geodynamics and other applications. The SLR global network is distributed in over 30 countries, with fixed and mobile stations. The ILRS Global SLR Network is made up of three regional networks: EUROLAS (European Laser Network) encompassing the European stations, NASA Network encompassing North America, and some stations in South America, South Africa and the Pacific and WPLTN (Western Pacific Laser Tracking Network) encompassing Japan, China, Eastern Russia and Australia.

\section{SLR SOUTH AMERICAN STATIONS}

In this work, another network consisting of four South American stations is proposed, shown in Figure 1. The Arequipa Station in Perú is the oldest one in the Southern hemisphere, code ILRS 7403 (set up in 1989). The ILRS 7407 Station in Brasilia is operational since 2014, and finally two stations

\footnotetext{
${ }^{1}$ Observatorio Astronómico Félix Aguilar, Universidad Nacional de San Juan, Benavidez 8175 Oeste, Chimbas 5413, San Juan, Argentina (pachecoanam@yahoo.com.ar).

${ }^{2}$ Universidad Nacional de San Agustín, Arequipa, Perú.

${ }^{3}$ Observatorio Argentino Alemán de Geodesia AGGO.
}

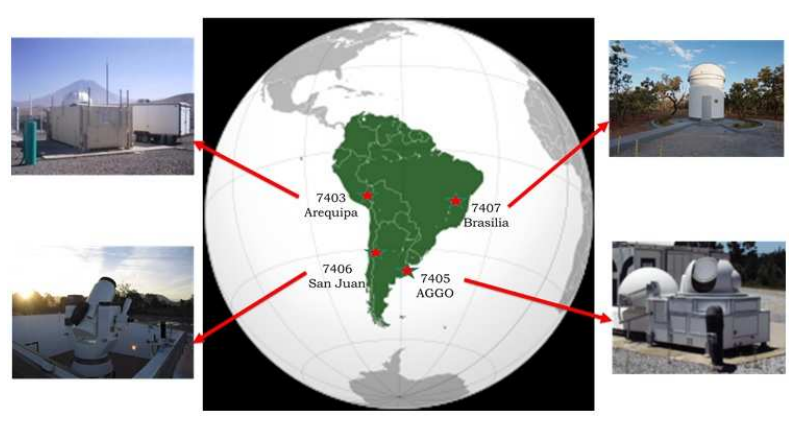

Fig. 1. South American Network.

in Argentina are operational as well, one of them, ILRS 7406 in San Juan (Pacheco et al. 2017) and the other one ILRS 7405 in La Plata, Buenos Aires, set up in 2006 and 2015, respectively. These stations are vital in the Southern hemisphere to contribute to the definition of reference systems (celestial and terrestrial), monitoring of Earth rotation, time scales, Geodynamics and other applications.

\section{FUTURE NETWORK PROJECT}

\subsection{Earth Rotation - Earth Orientation Parameters}

Four Latin American SLR stations contribute to the computation of the Earth Orientation Parameters, especially those of short period (Pacheco et al. 2015) Pole Coordinates (Polar Motion) and Universal Time (DUT1). 


\subsection{Seismicity of the South American network}

Seismic activity in the South American West is very high. Our SLR network can collaborate in this area, since it has two stations to the West (Arequipa and San Juan) located in the zone of greater seismic activity of the continent, and on the other hand the two stations of the East (Brasilia and La Plata) are located in the area of least seismicity, which can be uses as static reference points for the evaluation of cortical movements.

\subsection{Method of Short Arc}

For the analysis of seismicity and tectonic movements, the possibility of applying the Short Arc method to the SLR network is studied. This technique consists of tracking the same satellite simultaneously from two (or more) SLR stations and process only the simultaneous data. Sinclair and Appleby showed that this technique has great potential for accuracy, especially for monitoring the length of the baseline between participating stations with a 2-3 $\mathrm{mm}$ precision.

\subsection{Future Center of SLR data processing}

In Argentina, the possibility of processing GNSS and SLR data with the Bernese software is currently being studied, with the idea of including the OAFA and AGGO stations to the SIRGAS network. SIRGAS is the Geocentric Reference System for the Americas. Since its creation (1993), SIRGAS has worked only with the GNSS technique. The idea for the future is to include other spatial geodesic techniques, such as SLR, VLBI and DORIS, in the same way than the ITRF.

\section{CONCLUSIONS}

Because the number of SLR stations in the Southern hemisphere is very low, the few stations located in South America are particularly valuable. The future South American network will contribute to scientific studies of great relevance, guaranteeing the training and exchange of scientists, observers and technological advances.

\section{REFERENCES}

Pacheco, A., Podestá, R., Yin, Z., et al. 2015, RMxAC, 46,29

Pacheco, A., Podestá, R., Yin, Z., et al. 2017, RMxAC, 49, 143 